\title{
Teaching Managers To Relate: Using Feedback To Bolster Commitment And Morale
}

Donald C. Smith, University of New Haven

\begin{abstract}
Every text, indeed all writing in communication, either does or should stress the centrality of feedback in basic and advanced models of communication. Most work in this area has focused on taking feedback, distilling information and using it to make good decisions. What is lost in the traditional understanding is that feedback can be used to establish good relations. A manager's feedback can enhance employee/manger relationships, strengthen loyalty and commitment, and increase morale. This paper examines how managers can use feedback to make important and genuine connections with their employees; thereby getting the greatest return on human resources. A theory based "do and don't do" framework is offered. Establishing any good relationship is simply a matter of knowing what to say, how to say it, when and to whom. It's 9:00 a.m.; do you know who your employees are?
\end{abstract}

\section{INTRODUCTION}

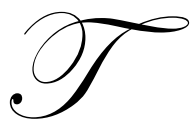

he paper before you is not an attempt to demonstrate how to condition employees to respond. It pays homage to neither Pavlov nor Skinner. It does not provide a scale to measure commitment or morale. The paper does not claim a manager can use the principles with an 80 or $90 \%$ reliability.

It does, however, organize insights around an idea that is intuitively appealing and which has what we might call "face validity." In short, this paper is what graduate school professors used to call a think piece. Hopefully, it has a heuristic value. Further, an end goal of this work is to help managers think before they speak and additionally give them some kind of framework within which to think before speaking, putting pen to paper, or entering keystrokes to screen. To this extent the paper before you is an extension of an earlier study which observed:

Communication education and training can lead managers to adopt the role of the expert spectator. The expert spectator knows to think before speaking, but more importantly, knows what to think about. This manager is in a better position to assess communication situations and figure out how to respond and knows it is unwise to focus on messages without first considering message users. (Smith 2003, p. 8).

A historical foundation will help the reader. In the days before communication studies came to favor quantitative methods to explain human behavior, the field was primarily qualititative in nature. A bold, well published colleague of mine, once asked the nature of his methodology, replied, "I think." He still managed to land a job at a fine university in Vancouver. This event occurred in the mid 1980s, one has to wonder how well this approach might be received in today's environment.

For Communication Studies the switch in methodology to quantitative methods grew progressively throughout the 1960s and 1980s, and likely came about as a genuine desire to try something new; a well intentioned effort to modernize the field. Quantitative analysis was used in Finance and Demographic research as early as the 1930s. For Communication Studies the method would proliferate in the 1980s despite the fact that punching computer cards was still the order of the day. We could only imagine the kind of resources we have available now. 
It is common knowledge that, at present, the typical PC on any student, household, or professional's desk is much more powerful than the formerly incredible Super Cray computers of the 1970s and 1980s which, in their time, were very fast and very expensive.

In pursuing grants which were most often awarded to the physical sciences, academicians in many behavioral science disciplines began to adopt this manner of study in hopes of procuring funds for their own work. Qualitative studies were thought to be "soft", even though no one was brash enough to level this criticism against the study of history and the conclusions subsequently drawn by historians. Additionally, on shaky ground would be critics trying to discount the published work of so many fine 20th century rhetoricians. Well written history and criticism is very valuable and most always qualitative. Labeling such work as "soft" would be ill warranted and advised.

One page of justification for the managerial approach discussed below, is hardly enough but will have to do for the scope of this paper. The current works looks at manger employee relationships and presents the case that climate is a socially constructed phenomenon; it is organic not mechanical. Further it looks at common kinds of feedback as viewed through the lens of a confirming v. disconfirming environment. Essential to this analysis is a discussion of open v. closed organizational environments and barriers generated by defensiveness. Also important is an understanding of the individual roles in corporate settings.

\section{ORGANIZATIONAL HOMEOSTASIS}

Organizations could not exist without communication. They are social constructions, the product of human desire and labor. Accepting this claim also means recognizing that any organization Digital, IBM, Yahoo, Google, MTV, HBO, is not what we would call a naturally occurring phenomenon. By this we mean, such business do not spring up from the ground. All organizations are the result of people planning and cooperating. All businesses, in a sense, are spoken into being and the corporate communication process is fluid, not static. Organizations are constantly renewing as members work to enact agreed upon values, missions, and division of work. For this reason many writers rightly conclude that organic not mechanical models are best for understanding organizational behavior.

Any healthy organization has a symbiotic relationship with its external environment. It takes things in, processes them, and then produces a product or service. Von Bertalanffy, a biologist, was first to postulate what would become known as systems theory.

A forgotten episode in Von Bertalanffy's apprenticeship is the culture-criticism which he wrote during the 1920's. Where the seeds of General System Theory are already visible. In reviewing books by the Viennese art historians, Josef Strzygowski and Max Dvorak, Von Bertalanffy lauded Oswald Spengler for having interpreted culture as an integrated system, within any culture, ideas and artistic forms interact with one another and with social institutions to simulate a common style. It is this process of interaction rather than its separate components which a historian of culture must study, For Spengler and for Strzygowski, a culture is what Von Bertalanffy would later call an "open system", digesting influences from without while undergoing interactions among its various levels. (Johnston, 1973).

Drawing on his training Bertalanffy observed that a change in one part of a system always provokes a change in another part. Should a right thumb be lost in an accident, for example, a shift would be made to using the left hand. Faced with starvation the human body begins to feed on calories stored for just such an event. An individual who loses sight will become more adept at hearing and feeling. All living things strive to achieve a balance. Even a rudimentary understanding of biology reveals that human beings take in food and oxygen, use it to our needs, and send the bi-product back out into the environment. Should this process become interrupted, the individual suffers and perhaps dies.

Every business, every formal organization, is influenced by this same principle. A company is born, matures, strives to survive, and sometimes does not. For this reason a tool to keep this complex social system balanced is not only desirable but essential. 


\section{COMMUNICATION AND ORGANIZATIONAL BALANCE}

All Communication and Management textbooks and articles recognize the centrality of communication in the success of organizations. Goldhaber speaks of communication as "the glue" glue that holds an organization together. As early as 1938 Chester Barnard argued that the first function of any executive was to establish and maintain a system of communication.

The writings of Karl Wick suggest that people in organizations "enact" various roles based upon the understanding that results from the communication process. Other works encourage management by wandering around (MBWA). Contact with employees is necessary for feedback and without it balance is virtually impossible. Curiously, while MBA programs recognize the importance of communication, they rarely have a full course in the subject area. It would appear that academicians in this area think a tacit understanding is enough.

To date, many of the traditional management programs in the United States seem not to view Communication, (the formal discipline) as among their important studies. Courses in this area are palpably absent and the accrediting agencies, AACSB for example do little to include the inclusion of communication courses in business school curriculum, (that is, at least insofar as the term is defined within the context of this paper and the communication discipline overall). Such absence can only be attributed to a lack of understating of the formal discipline of communication or the belief that its principles are sufficiently covered in other courses commonly offered by business schools and their programs. (Smith, 2003).

Curiously, even the most elaborate consulting firms display limited knowledge of the communication process. Consider the definition of communication on the home page of Six Sigma - an otherwise well developed analytical system. "Communication is the process of delivering and sending messages through various channels." That is all, no further explanation is offered. For purposes of this paper communication may be defined as: a tool for the co-creation of meaning which puts a frame around complex social phenomenon and helps both senders and receivers understand how to respond to organized expectations.

\section{COMMUNICATION BARRIERS}

Once, many years ago, the following conversation took place with a psychiatrist friend of mine. Him: "Your field is about making sure you're crystal clear or at least as clear as humanly possible before communicating with someone, right?" Me: "Yes, that is one way of viewing what we do." Him: "In my field we know that until someone is ready to hear something it doesn't matter what you say." The point begged the question, what then $\underline{i s}$ necessary to help someone arrive at the point where they are willing to listen? While there is no fast and easy answer, there is a way to create the conditions that best lead to a willingness to listen. Success in this regard centers upon Defensive v. Supportive Communication environments. Little wonder then, that Jack Gibbs's work on Defensive Communication found its way to over one million readers across a wide range of disciplines and corporations.

Defense arousal prevents the listener from concentrating upon the message. Not only do defensive communicators send off multiple value, motive and affect cues, but also defensive recipients distort what they receive. As a person becomes more and more defensive, he or she becomes less and less able to perceive accurately the motives, the values and the emotions of the sender. The writer's analysis of tape recorded discussions revealed that increases in defensive behavior were correlated positively with losses in efficiency in communication, (2).

The converse, moreover, also is true. The more "supportive" or defense-reductive the climate, the less the receiver reads into the communication distorted loadings which arise from projections of his own anxieties, motives and concerns. As defenses are reduced, the receivers become better able to concentrate upon the structure, the content and the cognitive meanings of the message. (Gibbs, circa 1988). 
In the very next section of this paper we take a look at the typology Gibbs suggests and correlate it to the things a manger would want to say, and want to avoid, so as to craft an open, defense free environment and in doing so create the best opportunities for free and honest exchanges of communication in the workplace.

\section{CONFIRMING V. DISCONFIRMING COMMUNICATION ENVIRONMENTS}

In a manner paralleling contemporary discussions of confirming versus disconfirming climates, Gibbs suggests six areas as important in the creation and maintenance of any corporate communication environment:

\begin{tabular}{|l|l|}
\hline \multicolumn{1}{|c|}{ Defensive Climates } & \multicolumn{1}{c|}{ Supportive Climates } \\
\hline 1. Evaluation & 1. Description \\
\hline 2. Control & 2. Problem Orientation \\
\hline 3. Strategy & 3. Spontaneity \\
\hline 4. Neutrality & 4. Empathy \\
\hline 5. Superiority & 5. Equality \\
\hline 6. Certainty & 6. Provisionally \\
\hline
\end{tabular}

What kinds of communication might flow from each category? Let us look at each in turn. First, is the defensive climate. 1. Evaluation: "You are not Magic Pan material," (Kelsey Grammar tells this story at length in his autobiography). 2. Control: "You will work this weekend because I am your boss and that is what I want you to do." 3. Strategy: "There is a level two administrative assistant position opening up in the Spring, I'd hate it if I was unable to recommend you." 4. Neutrality: "You stay, you stay, you leave you leave, either way it happens all the time." 5. Superiority: "There's a reason I have the corner office and you don't." 6. Provisionally: "Rule number one, I'm never wrong."

Next he outlines a typology for supportive climates. The reader will note a distinctly different feel in this kind of communication. 1. Description: "I do understand how important auditions are to you and I also need to be able to predict my staffing on any given night." 2. Problem Orientation: "The project has to be done by Monday and we're just about to run out of Friday, I'm open to alternate suggestions but I really feel your help this weekend could make all the difference". 3. Spontaneity: "Damn, you really are good at this!" 4. Empathy: "I understand, I've been there; let's take a look at the schedule and see if we can get you a block of time to take care of that problem." 5. Equality: "I don't expect you to get a cup of coffee for me unless you're getting one for yourself, and you'll find that I'll do the same in return," (Melanie Griffith does a superb job of illustrating this behavior in the 1980s hit film Working Girl). 6. Provisionally: "Let's explore both your approach and mine, whichever works out the best we can adopt."

\section{SIMPLE YET IMPORTANT CONSIDERATIONS}

Confirming communication is anything that causes a person to value themselves more; disconfirming communication is anything that causes a person to value themselves less (Tubbs, 2005). Such a consideration along with the Gibbs Typology and examples of category specific communications is essential for managers who truly wish to reach their employees. Disconfirming communication results in defensive behavior which in turn leads to communication barriers. The question a manager has to ask is, "are my employees defensive because of their nature, or have I done something to contribute to that state?" The former is possible as is the latter. Regardless, and 
in either case, it is very likely that small communication choices organized around the themes of this paper will help to unknot workplace tension and ameliorate the situation.

\section{CONCLUSION}

How then, might managers conceptualize corporate communication and the use feedback to establish positive and productive work relationships; thereby bolstering greater employee commitment and morale?

Seven principles are suggested:

First, recognize that organizations have a history and the people in them want to be remembered for their contributions.

Second, feedback ill phrased or poorly timed threatens organizational homeostasis and triggers psychological defenses.

Third, if an attempt is made to impede feedback, internally and/or externally, the organization is essentially operating as a closed system and this likely heralds its future demise.

Fourth, managers must strive to create conditions under which everyone feels free to listen and contribute to the communication process.

Fifth, communication is a learned behavior, and as such, greater success can be achieved by paying attention to best practices; those which break down communication barriers as opposed to shoring them up. Members at every level of an organization can be taught communication skills and concepts that when understood and applied properly will serve the best interest of each employee and the company as a whole.

Sixth, managers must avoid the "illusion of participation". If meetings are held under the pretense of seeking input when a decision has already been made, the meeting ought to be explicitly cast in that light. If not, perceptive employees will feel that they have been deceived, have had their attendance wasted, and in time a general learned helplessness will fall upon the workforce. Why exercise independent thought and action if each meeting suggests that doing so is pointless?

Finally, quantitative data in an organization provides only a piece of the information available, a snapshot of organizational behavior taken at a particular place and time. Therefore it is vital for managers to work from a well informed qualitative understanding of organizational reality in day to day communications between and among employees.

\section{REFERENCES}

1. Barnard, Chester (2007). The Functions of the Executive. Harvard University Press, anniversary edition.

2. Gibb, Jack (1966). Defensive Communication. National Training Laboratories, Unknown Binding. Retrieved from: www.geocities.com/toritrust/defensive communication.htm

3. Goldhaber, GM. (1993) Organizational Communication. Brown \& Benchmark.

4. Grammar, Kelsey (1996). So Far. Hamish Hamilton LTD. (Abridged audio version can be ordered through amazon.com).

5. Johnston, William N. "Von Bertalanffy's Place in Austrian Thought," in Unity Through Diversity. ed. by William Gray and Nicholas D. Rizzo, New York: Gordon and Breach. (excerpt retrieved from: http://generalsystemstheory.bravehost.com/).

6. Six Sigma (2007). Retrieved from www.sixsigma.com/dictionary/Communication-521.htm.

7. Smith, Donald C. (2003). Communication, Management and the Role of the Expert Spectator, Australia New Zealand Communication Association Conference, Brisbane.

8. Tubbs, Stewart L. (2005) A Systems Approach to Small Group Interaction. New York: McGraw-Hill. 
9. Weick, Karl (1995). Sensemaking in Organizations. Sage Publications.

\section{$\underline{\text { NOTES }}$}

